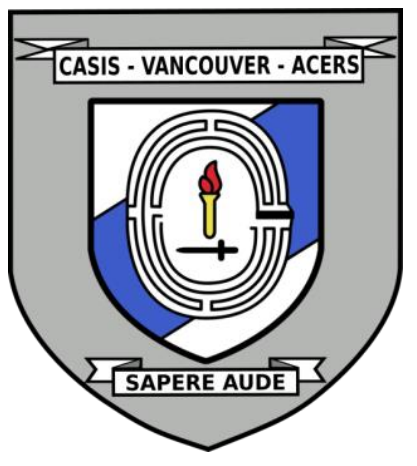

\title{
CANADIAN INTELLIGENCE FOR THE DANGEROUS DECADES
}

Date: November 23, 2021

Disclaimer: This briefing note contains the encapsulation of views presented by the speaker and does not exclusively represent the views of the Canadian Association for Security and Intelligence Studies.

\section{KEY EVENTS}

On November 23, 2021, Mr. Greg Fyffe presented Canadian Intelligence for the Dangerous Decades at the 2021 CASIS West Coast Security Conference. The presentation was followed by a question and answer period with questions from the audience and CASIS Vancouver executives. The key points of discussion included an overview of Mr. Fyffe's most recent report on the structure of the Canadian intelligence system and points of improvement for both the Canadian intelligence system as well as the national security strategy.

\section{NATURE OF DISCUSSION}

\section{Presentation}

The main theme of Mr. Fyffe's presentation was the analysis of the current Canadian intelligence system and how to improve it by taking into consideration current and potential threats. By providing a framework of analysis on some international security issues and drawing upon his most recent report on the structure of the Canadian intelligence system, Mr. Fyffe provided specific recommendations, which he stated could significantly improve the intelligence system and its culture.

\section{Question Period}

During the question and answer period, Mr. Fyffe talked about the need to protect democratic conversations regarding Canadian intelligence, by having understood and accepted procedures for dealing with sensitive information. Mr. Fyffe also discussed the importance of having a stronger central capacity to manage national 
security issues, more transparency of the intelligence system, and the importance of political oversight.

\section{BACKGROUND}

\section{Presentation}

Mr. Fyffe began his presentation by discussing his most recent publication titled Prepared: Canadian Intelligence for the Dangerous Decades, which looks at reimagining the national security strategy and the readiness of the Canadian government to improve the intelligence system. Mr. Fyffe noted that this report is part of a project at the Centre for International Governance Innovation (CIGI), that draws on different perspectives and international experts.

Mr. Fyffe emphasized the increasing importance of an active foreign policy for Canada and the need for strong intelligence support. Traditionally, Canada has been 'protected' by being geographically isolated; it shares its border with the United States (U.S.), but it has no adjacent enemies as many other countries do. In addition to this now outdated sense of safety, the high turnover in foreign policy and intelligence leadership positions creates instability and makes it difficult to develop a strong intelligence culture and capability. Mr. Fyffe argued that as we enter a period of intense and prolonged danger, foreign policy will be relevant ways that it has not been before.

Although the happenings on the global stage may not have always been a political priority for Canada, Mr. Fyffe indicated that a shifting landscape will gradually bring an enormous impact on the lives of Canadians. Mr. Fyffe expanded on several contemporary security issues that are relevant and important to Canadians. Global warming, for example, will last for decades and will have long-lasting effects and potentially cause conflict all around the world. Furthermore, a high level of pandemic danger will continue. There is constant cyberwar and great economic consequences for the countries attacked; international and domestic terrorism; constant online fraud and ransomware; foreign interference in electoral processes; ethnic conflicts; and conspiracies that interfere with health crises management. All these security issues have demonstrated that the international environment is becoming more relevant and important in the lives of Canadians. It is crucial that foreign policy is engaged with global issues of concern to our allies, including those generated by China, Russia, Iran, and the Democratic People's Republic of Korea. 
Several aspects have made the geopolitical environment increasingly dangerous. For instance, although the current situations in Taiwan and Ukraine are at the strategic level, it is difficult to predict how these situations will evolve. As foreign policy becomes more important, Canada needs to be more active and find solutions. However, it is important to note that foreign policy needs to be backed up by quality intelligence, as it is for all of our allies.

Mr. Fyffe further stated that the intelligence system needs to be more attuned to warnings, which are often put on the backburner when immediate crises demand more attention. If a specific body were to be assigned to look at warnings, it could create actionable intelligence to help highlight potentially dangerous developments, and it could outline potential reactions if the situations became more serious. An intelligence community that is action-coherent, highly organized, and agrees with decision-makers on strategic situations can accomplish steady and cumulative incremental changes that, in combination, can create substantial increased efficacy for the whole system. In addition, Mr. Fyffe noted that a government review of the Canadian security and intelligence system and regular reports on national security are needed and long overdue.

Another recommendation in Mr. Fyffe's report is for Canada to take into serious consideration the idea of building a national security committee, which would provide the stability needed for the intelligence system. National security committees often have different meanings in different countries. A Canadian committee should incorporate some of the components used by allies such as the United Kingdom, the United States, and Australia while meeting Canadian needs and constitutional structures.

Mr. Fyffe concluded his presentation by noting that if the government of Canada were to consider CIGI's initiative on security policy, it would lead to good strategic and tactical warnings, improve the intelligence culture, and support a strong foreign policy backed up by intelligence. While these changes would incur costs, that should not prevent discussion on major changes to the system. Some improvements could be achieved with relatively low expenditures. Canada's structure is far behind its allies and it is too siloed, which hurts strategic thinking and warning. Canada seems to be determined to make an impact with an increased emphasis on an activist foreign policy, but the impact needs to be broader and across many global issues, including security issues. 


\section{Question Period}

During the question and answer period, Mr. Fyffe noted that since information operations can manipulate individuals' reputation, accuse the government of things it is not guilty of, or try to create conflict between ethnic groups, a reliable information validation authority is needed. Given that governmental intervention in certain situations would often be undesirable or lack credibility, Mr. Fyffe suggested that a private organization, possibly with some governmental support, could be created in the interest of protecting democratic conversations and truth. Additionally, he indicated that balance between national security needs and individual rights and freedoms is crucial.

The government of Canada needs to do more to ensure that there is more understanding and support of national security and intelligence and the security issues. Mr. Fyffe expressed that Canada should, to a degree, imitate what the United Kingdom, the United States, and Australia are doing by putting out a regular government-wide statement on the current security landscape and positioning national priorities in the global context. However, this has been discouraged by the current practice which has not embraced comprehensive, blunt statements on the overall security environment. Mr. Fyffe also emphasized that the National Security and Intelligence Committee of Parliamentarians is an important instrument for informing parlementarians and all Canadians. It is an important instrument for highlighting desirable improvements in the system.

Mr. Fyffe also stated that there is a paradox in promoting system transparency. A government is more likely to accept challenging assessments when they are not public. This means that some kinds of documents can be released while others are protected. The US, by contrast, is much more open about some intelligence conclusions, but there is a greater danger that a government will suppress or even change assessments it does not agree with.

With respect to evidence-based decision-making on foreign policy procedures, Mr. Fyffe pointed out that there are different kinds of evidence that originate from different sources. While decision making drawing on relevant intelligence evidence is always desired, diplomats have different sources of information and make judgments based on different reasoning. From an intelligence point of view, analysts should provide the best intelligence possible but not with the belief that it is the definitive word.

The Journal of Intelligence, Conflict, and Warfare Volume 4, Issue 3 


\section{KEY POINTS OF DISCUSSION}

\section{Presentation}

- Support of Canada's foreign policy within the intelligence community plays an important role in the success of foreign affairs.

- Security issues such as pandemics, cyberwar, terrorism, online fraud, conspiracies, and many others have demonstrated that the international environment is becoming more relevant in the lives of Canadians.

- It is difficult to predict how the geopolitical environment will evolve, but as foreign policy becomes more important, Canada needs to be more active and work actively with allies to develop solutions.

- Foreign policy needs to be backed up by quality intelligence.

- An intelligence community that is action-coherent, highly organized, and agrees with decision-makers on strategic situations can accomplish incremental changes to improve the whole system.

\section{Question Period}

- It is important to balance individual rights and freedoms with national security needs.

- The Canadian national intelligence and security strategy needs to be supported by a stronger governmental and public intelligence culture.

- The Canadian intelligence system is less politicized than the US one, but how the system must operate and what it needs to accomplish is not always well understood.

- While foreign policy decision-makers should have access to high quality intelligence, diplomats have access to many sources of information and their factual and policy conclusions may justifiably vary from those made from an intelligence perspective. 


\section{(c) (i) ()}

cC) This work is licensed under a Creative Commons Attribution-NonCommercial-NoDerivatives 4.0 International License.

(C) (GREG FYFFE, 2022)

Published by the Journal of Intelligence, Conflict, and Warfare and Simon Fraser University

Available from: https://jicw.org/ 